\title{
Miniorações em anúncios sob a perspectiva discursivo-funcional
}

\author{
Erotilde Goreti Pezatti ${ }^{a}$
}

\begin{abstract}
Resumo
A proposta é investigar estruturas de miniorações da perspectiva da Gramática Discursivo-Funcional, desenvolvida por Hengeveld e Mackenzie (2008), em ocorrências reais de uso, extraídas de anúncios dos séculos XIX e XX. O fenômeno investigado consiste em ocorrências constituídas de dois sintagmas, que se relacionam com a estrutura informacional Tópico-Foco, como em Piscina gelada... nunca mais. que apresentam os seguintes traços: (i) são construções comuns nas linguas; (ii) exigem um tipo de estudo que não se concentre em frases isoladas, uma vez que dependem da situação em que se acham falante ouvinte; e (iii) submetem-se a regras e princípios intraoracionais. A seleção desse tipo de estrutura constitui uma estratégia de adaptação aos objetivos comunicativos do usuário na interação, tanto em termos de formulação pragmática e semântica, quanto em termos de codificação morfossintática e fonológica, tal como predito pela GDF.

Palavras-chave: gramática funcional. minioração. sintagma. frase nominal.
\end{abstract}

${ }^{a}$ Universidade Estadual Paulista (UNESP), Instituto de Biociências, Letras e Ciências Exatas (IBILCE) - São José do Rio Preto-SP- Brasil, Departamento de Estudos Linguísticos e Literários. Bolsista PQ-CNPq: Proc. No. 305753/2013-4. E-mail: erotilde.pezatti@unesp.br. 


\section{Introdução}

Um tipo de construção pouca investigada na literatura funcionalista são frases nominais como Piscina gelada... nunca mais, assim denominadas pela tradição gramatical por se tratar de frases destituídas de um verbo.

Benveniste (1976, p. 163) afirma que a frase nominal é considerada uma expressão normal do indo-europeu, caracterizada por um predicado nominal, sem verbo nem cópula. Assim, nas frases nominais, as duas funções do verbo, a função coesiva, que consiste em organizar numa estrutura completa os elementos do enunciado, e a função assertiva, que dá ao enunciado de um predicado de realidade, recaem sobre um elemento da classe morfológica dos nomes, não sendo a frase suscetível das determinações que a forma verbal tem em si, como tempo, modo e aspecto. Dessa maneira, o enunciado será caracteristicamente atemporal, impessoal, não modal. Para Benveniste (1976, p. 176), a frase nominal no indo-europeu, por ser sentenciosa e expressar uma verdade absoluta, não apresenta relação com o tempo nem com o locutor. Sendo verdade absoluta, é inserida no discurso não para ser discutida, mas para provar, convencer. Hjelmslev (1972, p. 172), por seu turno, sustenta a ideia de que é possível haver predicação na ausência do lexema verbal. Assim, as frases nominais podem ser predicativas, como, por exemplo, Bem caseira a comida, e não predicativas, conforme Silêncio! As primeiras, chamadas dirremas, têm sujeito explícito, enquanto as últimas, os monorremas, não.

Segundo Carone (1986, p. 47), as construções linguísticas podem representar tipos frasais, que se apresentam num continuum de complexidade morfossintática. Todos os tipos são considerados frases, já que portam um sentido e contam com uma modulação que lhes confere tal estatuto. Desse modo, há expressões constituídas de "qualquer dos elementos secundários que, na oração, se organizam em torno do verbo" (CARONE, 1986, p. 48), que são chamadas de reses ou frases nominais unimembres, como $O$ crime do padre Amaro. Um pouco mais complexa do que a rese é a frase nominal bimembre, designada dirrema, como Inúteis os cuidados com os bichos moribundos (CARONE, 1986, p. 50). O dirrema, também desprovido de verbo, apresenta dois elementos que se 
${ }^{1}$ Ainda que o conceito de modulação prosódica da autora não seja necessaria mente equivalente à pausa, esse tipo de acidente prosódico ocorre frequentemente na fala espontânea, sem, contudo, a regularidade distribucional que identifica os dirremas para Carone (1986).

${ }^{2}$ Ocorrências extraídas do Banco de Dados Iboruna, constituído de dois tipos de amostra: AC (Amostras Censo de entrevistas) e AI (Amostras de Interação dialógica livre).

${ }^{3}$ A explicação sobre esse fenômeno gramatical apresentada neste estudo difere do de Fortilli (2007). relacionam à semelhança de sujeito e predicado, denominados tema e rema. Tomando a expressão "Próxima estação, Liberdade", Carone (1986, p.50) afirma que a modulação da frase, apoiada na pausa, indica que não se trata de substantivo e adjunto e, por isso, a modulação é um componente sintático suprassegmental que funciona como verbo da frase nominal. ${ }^{1}$

Mais recentemente, essas construções destituídas de predicado verbal têm chamado a atenção de outros linguistas de orientações teóricas distintas. Do ponto de vista formalista, que não é o assumido aqui, estruturas bimembres, como muito bonita a cidadezinha (AC-69, 184), ${ }^{2}$ são denominadas small clauses ou miniorações e têm sido tratadas, entre outros, por Kato (2007), Pinheiro (2009,), Sibaldo (2011) Zendron da Cunha e Carpes (2015), cuja preocupação reside em explicar o fato de essas estruturas comportarem grande complexidade formal e também restrições no apagamento da cópula. Do ponto de vista funcionalista, encontram-se os trabalhos de Mackenzie (1998), que trata de estruturas unimembres, denominadas holófrase; Pezatti, D’Annibale e Boiago (1999), que verificam o uso dessas estruturas na linguagem da propaganda; Fortilli (2007), para quem construções não verbais são frequentes em situações em que o falante descreve ou julga algo e conferem mais vivacidade ao discurso; e Pezatti (no prelo), que trata de holófrases em anúncios dos séculos XIX e XX, tomando como suporte a Gramática Discursivo-Funcional. ${ }^{3}$

Neste trabalho, debruçamo-nos sobre estruturas bimembres, que não apresentam cópula, mas, diferentemente das miniorações, como muito bonita a cidadezinha (AC-69, 184), se estruturam como em e eu... rainha absoluta né?... (AC-150, 126). O objetivo é descrever essas construções sob uma perspectiva funcionalista, mostrando que (i) são construções especialmente comuns na linguagem da propaganda; (ii) exigem um tipo de estudo que não se concentre em frases isoladas, uma vez que dependem da situação em que se acham falante e ouvinte; mas (iii) submetem-se a regras e princípios intraoracionais.

O modelo funcionalista aqui adotado, o da Gramática Discursivo-Funcional (HENGEVELD; MACKENZIE, 2008), caracteriza-se por considerar muito seriamente o postulado de que os enunciados são produzidos e entendidos no contexto de interação. Assim, para a análise, são utilizadas ocorrências reais extraídas de anúncios, notícias e propagandas, considerando 
que, conforme Jubran (1985, p. 27), o objetivo do anúncio é o de substituir longos discursos, que requerem uma decifração custosa em tempo e em atenção, para uma imagem mais incisiva, o que propicia a ocorrência dessas estruturas. Segundo Pezatti (1988, p.12), "a linguagem da propaganda se caracteriza principalmente por ser objetiva: convencer o receptor e obter um consenso emotivo que se traduzirá na adesão dele às suas propostas. Para isso utiliza a linguagem, transformando-a em ação específica e particular de persuadir."

Os exemplos que servirão de evidência são ocorrências extraídas do corpus do Projeto para a História do Português Brasileiro, dos séculos XIX e XX, que se encontram catalogados na Plataforma de Corpora, disponibilizado na página <https:// sites.google.com/site/corporaphpb>. Quando necessário, no entanto, para melhor fundamentar a discussão, recorremos a ocorrências extraídas da internet, com a mesma datação, de sites como <publicinove.com.br/70-slogans-criativos-demarcas-famosas-para-voce-se-inspirar/> e <https://www. mensagenscomamor.com/frases-de-propaganda>.

Este texto se organiza em duas partes: a primeira trata do arcabouço teórico, com uma breve apresentação geral da Gramática Discursivo-Funcional (GDF); a segunda parte privilegia as construções formadas por dois constituintes, destituídas de verbo, a que se denomina equiordenação sintagmática. Encerram este estudo as Considerações Finais, em que se faz um balanço dos resultados.

\section{Suporte teórico: a Gramática Discursivo-Funcional}

A finalidade desta seção é introduzir alguns postulados da Gramática Discursivo-Funcional (GDF) que permitam fornecer os fundamentos necessários para a discussão das frases nominais. A Fig. 1 representa a arquitetura geral do modelo, conforme proposta em Hengeveld e Mackenzie (2008). 
Figura 1 - Layout Geral da GDF

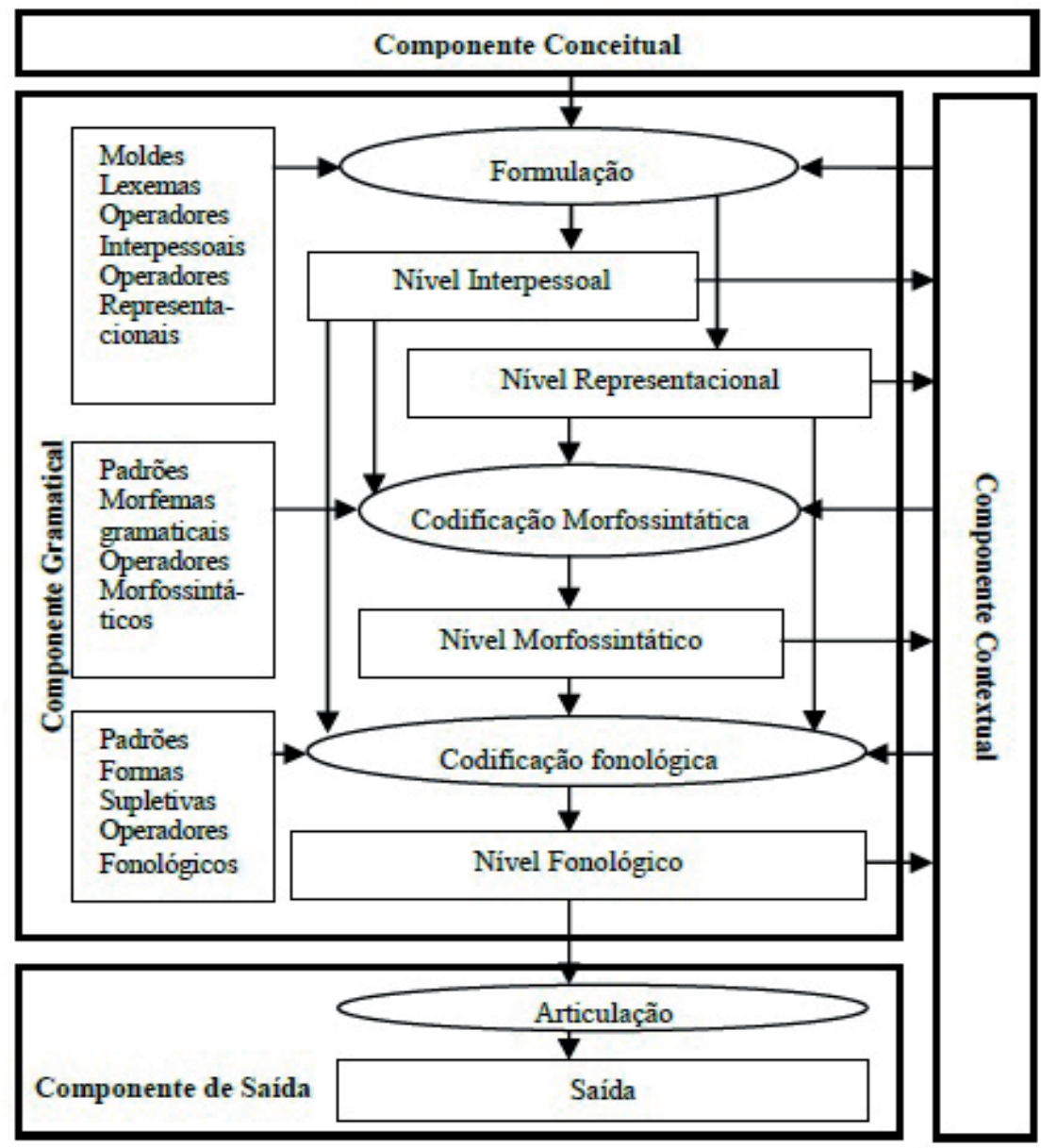

Fonte: Adaptado de HENGEVELD \& MACKENZIE, 2008: 13.

A GDF consiste num modelo descendente, o que significa que a construção de um enunciado padrão em situação de interação se inicia com a intenção comunicativa de uma mensagem no Componente Conceitual; ainda nessa forma prélinguística, a mensagem passa para o Componente Gramatical, em que é formulada em unidades de conteúdo pragmático e semântico e codificada em unidades formais de natureza morfossintática e fonológica.

Essa direção descendente é motivada pela suposição de que um modelo de gramática será mais eficaz quanto mais sua organização assemelhar-se ao processamento linguístico no indivíduo. O modo descendente de organização implica que cada estágio ou componente por que passa a mensagem nesse processo constitui a entrada do estágio ou do componente 
seguinte. Nesse caso, o componente conceitual fornece a entrada para o componente gramatical que, por sua vez, fornece a entrada para o componente de saída, em que a mensagem é finalmente articulada.

O componente conceitual é a força motriz do componente gramatical como um todo, uma vez que é responsável pelo desenvolvimento tanto da intenção comunicativa relevante para o evento de fala corrente, quanto das conceitualizações associadas a eventos extralinguísticos relevantes. O componente de saída gera as expressões acústicas ou escritas com base na informação fornecida pelo componente gramatical. O componente contextual contém a descrição da forma e do conteúdo do discurso precedente, do contexto real do evento de fala e das relações sociais entre os participantes.

Na formulação, o nível interpessoal (NI) representa a ação linguística do falante em evocar referentes e em atribuir propriedades para conseguir seu objetivo comunicativo. $\mathrm{O}$ sequenciamento de ações linguísticas reflete a ordem das estratégias colocadas em prática pelo falante para atingir seu objetivo comunicativo. Esse nível é constituído de várias camadas hierárquicas: o movimento, o ato discursivo, a ilocução, o conteúdo comunicado e os subatos referencial e atributivo. Particularmente de interesse para este trabalho é a camada do ato discursivo, a menor unidade identificável de um comportamento comunicativo, que corresponde a uma unidade de entonação. É a unidade básica do discurso, que pode ter diferentes graus de complexidade, desde interjeições, como nossa! (AC-51, 216), holófrases, como PALHAÇO! (AC-87, 134), até orações simples, como a gente ia no jardim (AC-130, 41), e complexas, como aí fomos nessa palestra voltamos e janTAmos né? (AC-51, 216).

De modo geral, o ato discursivo é composto de uma ilocução e de um conteúdo comunicado. A ilocução apreende as propriedades formais e lexicais do ato discursivo que podem ser atribuídas a um uso interpessoal, convencionalizado para representar uma intenção comunicativa. As intenções comunicativas podem ser de diversos tipos, como chamar a atenção, afirmar, dar ordem, questionar, alertar, requerer etc. Esses tipos de intenção comunicativa podem ser expressos por meio de interjeição, verbo performativo e ilocução abstrata. O conteúdo comunicado, por seu turno, contém tudo o que 
o falante deseja evocar na interação com o ouvinte, sendo constituído, por sua vez, de um ou mais subatos. Subatos representam uma forma de ação comunicativa do falante e são assim chamados porque são hierarquicamente subordinados ao ato discursivo. Subatos podem ser de atribuição (T) e de referência (R). O primeiro expressa uma tentativa do falante de evocar uma propriedade, como correr, bonito, azul, que se pode aplicar a uma entidade. Já o segundo, constitui uma tentativa do falante de evocar um referente, ou seja, um conjunto nulo, único ou múltiplo de entidades, como caderno, mesa, cidade, casa, festa, reunião, crença, ideia, razão. Um conteúdo comunicado deve conter pelo menos um subato. Neste estudo, trataremos de atos discursivos, cujo conteúdo comunicado é constituído por dois subatos, que podem ser ambos referenciais, ambos atributivos ou um referencial e outro atributivo.

Já o nível representacional (NR) trata dos aspectos semânticos das unidades linguísticas, quer referentes ao modo como a língua se relaciona ao mundo extralinguístico que ela descreve, quer aos significados de unidades lexicais, independentemente do modo como essas unidades são usadas na comunicação. Esse nível é também constituído de várias camadas hierárquicas. A unidade mais alta é o conteúdo proposicional, um construto mental, que pode conter um ou mais episódios, que, por sua vez, são conjuntos de estados de coisas tematicamente coerentes, no sentido de que apresentam unidade ou continuidade de tempo, lugar e indivíduo. Estados de coisas incluem eventos e estados que se caracterizam por serem localizados no tempo e avaliados em termos de seu estatuto de realidade. Um estado de coisas é estruturado sobre uma propriedade configuracional, que tem natureza composicional e contém uma combinação de unidades semânticas que não estão em relação hierárquica entre si, e constitui a unidade de análise de maior interesse neste estudo. Há também camadas não hierárquicas, constituídas do predicado e seus argumentos, que são as seguintes: a propriedade (f), que não tem existência independente e pode somente ser avaliada em termos de sua aplicabilidade a outros tipos de entidades ou à situação que ela descreve em geral; o indivíduo (x), designa uma entidade de primeira ordem, que pode ser localizada no espaço e avaliada em termos de sua existência; lugar (l) que indica um espaço físico; tempo (t), uma 
categoria semântica que pode tanto estar ligada à interpretação contextual no momento de fala, como a posições relativas na linha do tempo, ao calendário estabelecido socialmente, a um ponto ou a um trecho na linha do tempo; maneira (m), que indica o modo como o estado de coisas é executado; quantidade (q), que designa o montante de fenômenos contáveis e incontáveis; e razão (r), que representa pensamentos que orientam um agente humano para agir de certa maneira.

Na operação de codificação, o nível morfossintático (NM) tem como tarefa tomar o input duplo resultante da formulação dos níveis interpessoal e representacional e fazêlo emergir em uma única representação estrutural. Assim, a codificação morfossintática converte unidades de significado em unidades morfossintáticas, que, pela codificação fonológica, são convertidas em unidades fonológicas. Igualmente aos níveis da formulação, os níveis da codificação são compostos por camadas hierárquicas: o nível morfossintático contém as camadas da expressão linguística, da oração, do sintagma e da palavra, e o nível fonológico (NF) contém o enunciado, a frase entonacional, a frase fonológica, o pé e a sílaba.

De interesse para este estudo é a expressão linguística, a camada mais alta do nível morfossintático, e referese a qualquer conjunto constituído de, pelo menos, uma unidade morfossintática, que pode ser oração, como nunca fui a Pernambuco (Bras80: Arte Urbana), um sintagma, como que horror! (PT72: Ao Volante), ou palavra, como coitadinho! (Bras80: Criar Filhos). Quando houver mais de uma unidade na expressão linguística, elas terão as mesmas propriedades morfossintáticas, já que não são partes uma da outra, permitindo várias combinações. A combinação de orações pode resultar em coordenação, cossubordinação ou equiordenação oracional; já a combinação de uma oração com um sintagma se denomina extraoracionalidade. O que particularmente nos interessa neste estudo, no entanto, é a combinação de dois sintagmas, que resulta na equiordenação sintagmática, em que os dois sintagmas envolvidos são mutuamente dependentes, como em e o Zé TOdos os dias na minha casa... (AC -130, 41).

A oração constitui outra camada do NM, que, considerada uma categoria universal da estrutura morfossintática, constitui

${ }^{4}$ Esse tipo de estrutura é tradicionalmente denominado Correlação. um grupo de um ou mais sintagmas, caracterizados, em maior ou menor extensão, por um padrão de ordenação e 
por expressões morfológicas de conectividade, notadamente concordância e regência. Em outras palavras, para a GDF, a oração consiste em uma configuração sequenciada de palavras (por exemplo, Um café?), sintagmas (como Você quer um café?) e outras orações (conforme Ela disse que quer um café.)

A camada abaixo da oração é a do sintagma, que, assim como a oração, consiste potencialmente em uma configuração sequenciada de palavras, de outros sintagmas e de oração encaixada. É formado por um núcleo lexical, oriundo do nível interpessoal ou representacional; como entidade lexical, seu núcleo pode ser um verbo (Vp - Verb Phrase), um substantivo (Np - Noun Phrase), um adjetivo (Adjp - Adjective Phrase), um advérbio (Advp - Adjverb Phrase), ou uma adposição (Adpp - Adposition Phrase). A adposição pode ser anteposta (Prep Preposition Phrase) ou posposta (Posp - Posposition Phrase) a um nome. No caso do português, a adposição é sempre anteposta.

\section{Enfoque discursivo-funcional das miniorações}

Para a GDF, a pragmática comanda a semântica, a pragmática e a semântica determinam a morfossintaxe, e a pragmática, a semântica e a morfossintaxe moldam a fonologia, já que a construção de um enunciado padrão em situação de interação se inicia com a intenção comunicativa de uma mensagem, uma forma ainda pré-linguística, que é formulada em unidades de conteúdo pragmático e semântico e depois codificada em unidades formais de natureza morfossintática e fonológica. Assim considerando, esta seção tratará das propriedades pragmáticas, semânticas, morfossintáticas e fonológicas dessas construções.

\subsection{Análise pragmática}

No corpus utilizado para análise, verificam-se ocorrências como (1), em que facilmente se pode constatar a existência de dois constituintes relacionados: antárctica, que serve de suporte

5 As ocorrências estão rigorosamente reproduzidas conforme aparecem no corpus de onde foram extraídas, com barras simples e duplas que indicam a disposição gráfica. para a enunciação do constituinte simplesmente a melhor, que traz a informação relevante.

(1) ANTARCTICA | Simplesmente a melhor.

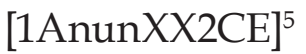


Esse tipo de enunciado, da perspectiva da GDF, constitui, no nível interpessoal, um movimento, uma vez que, em termos de seu estatuto interacional, representa uma contribuição autônoma para a interação em desenvolvimento, com um efeito perlocutório, já que é em si mesmo uma reação ou abre a possibilidade de reação. Esse efeito perlocutório é próprio da linguagem de anúncios e propagandas, pois, como observado por Pezatti (1988, p. 12), o objetivo do anúncio é persuadir o destinatário das boas qualidades de um produto e conseguir sua adesão.

Estruturas como (1) pertencem a um movimento, cujo núcleo é composto de um único ato discursivo, ou seja, representa uma unidade de comunicação, correspondente a uma unidade de entonação. Em outras palavras, o enunciado (1) envolve um falante e um destinatário e é composto de uma ilocução, que representa uma intenção comunicativa, e de um conteúdo comunicado, constituído, por sua vez, de dois subatos.

No corpus analisado, o tipo de ato discursivo aqui enfocado apresenta sempre ilocução declarativa, uma vez que apenas informa o destinatário do conteúdo proposicional evocado pelo conteúdo comunicado, conforme mostram a ocorrência (2) e as expressões em negrito em (3) e (4).

(2) UM PRESENTE RÉGIO | PARA O DIA | DAS MÃES || COLCHÕES DE MOLAS | DIVINOBEL |(1AnunXX2CE)

(3) Tambem (sic) pelo custo, papel enveloppes (sic), tinta, cadernetas etc. | As vendas pelo custo são só à (sic) dinheiro. | Rua 2, casa número 46. (A Notícia, dezembro de 1898)

(4) SOLTEIRO à vista apenas 115,00 ou 10.80 mensais | CASAL à vista somente 160,00 ou 15.30 mensais | FABULOSA OFERTA PROBEL | FEIRA DAS CAMAS | F. PEIXOTO, 794 FONES: 21-21-12 - 2156-83. (1AnunXX2CE)

O que caracteriza esse tipo de construção, no nível interpessoal, é que a cada um dos subatos se atribui uma função especial no ato discursivo, ou seja, uma função pragmática. 
Da perspectiva da GDF, a atribuição de função pragmática a unidades linguísticas constitui uma estratégia do falante para atingir seu objetivo comunicativo. As estratégias de natureza intencional referem-se à pragmática. A pragmática, diferentemente da retórica, explica o modo como o falante modela as suas mensagens em relação às expectativas que tem do estado mental do destinatário. Esse procedimento determina as partes de uma unidade linguística que serão apresentadas como particularmente salientes, as que são escolhidas como ponto de partida do falante e as que são consideradas compartilhadas pelo falante e pelo destinatário. Assim, as funções pragmáticas foco, tópico e contraste, propostas pela GDF, constituem aspectos formais da unidade linguística que reflete seu papel na interação entre falante e destinatário. Neste estudo, interessam-nos especialmente as funções pragmáticas tópico e foco.

O tópico, segundo Hengeveld e Mackenzie (2008, p. 92), assinala como o conteúdo comunicado se relaciona ao registro gradualmente construído no componente contextual; em outras palavras, o tópico é o reflexo linguístico de uma instrução para o destinatário resgatar uma informação no cotexto ou no contexto situacional. Essa função pode ser aplicada tanto ao subato referencial quanto ao atributivo. Nas construções aqui tratadas, é possível observar que o subato que inicia o ato discursivo instrui o destinatário a resgatar uma informação no cotexto ou no contexto situacional para então atribuir-lhe a informação relevante contida no subato seguinte. Assim, nas ocorrências (1), (2), (3) e (4), o primeiro subato, respectivamente Antarctica, presente, pelo custo e solteiro, fornece um ancoramento consistente ao subato seguinte, que traz a informação relevante.

O segundo subato, por outro lado, sinaliza, na interação, a seleção estratégica do falante de uma informação nova, avaliada como essencial para ser integrada na informação pragmática do destinatário, preenchendo assim uma lacuna de informação. Em outros termos, constitui uma instrução de atualização do destinatário. Esse constituinte veicula, então, a função pragmática foco, que pode, assim como o tópico, ser aplicada tanto ao subato referencial quanto ao atributivo. Nas ocorrências em (1), (2), (3) e (4), os subatos respectivamente [a melhor (cerveja)], [colchões], [papel, envelopes, tinta, cadernetas] e [115,00 ou 10.80 mensais] veiculam essa função pragmática. 
Assim considerando, as construções aqui tratadas constituem um molde de conteúdo contendo um tópico e um foco, conforme representado em (5), em que SA indica subato; N, um número indefinido; TOP, a função pragmática tópico, e FOC, a função pragmática foco, podendo ser representadas conforme (1a), (2a), (3a) e (4a).

$$
\left[(\mathrm{SA})^{\mathrm{N}}(\mathrm{SA})_{\mathrm{TOP}}(\mathrm{SA})_{\mathrm{FOC}}\right]
$$

$(\mathrm{SA})_{\text {TOP }}$

(1)a antárctica

(2)a um presente régio para o dia das mães

(3)a também pelo custo,

(4)a solteiro
$(\mathrm{SA})_{\mathrm{FOC}}$

simplesmente a melhor

colchões de molas divinobel

papel enveloppes, tinta, cadernetas etc.

à vista apenas 115,00 ou 10.80 mensais

Como se vê, o que caracteriza esse tipo de construção é a atribuição de funções pragmáticas, o que permite ao falante atingir seu objetivo comunicativo de modo rápido, substituindo "longos discursos, que requerem uma decifração custosa em tempo e em atenção, para uma imagem mais incisiva". (JUBRAN, 1985, p. 31).

\subsection{Análise semântica}

No nível representacional, os subatos que compõem o ato discursivo podem apresentar como núcleo a categoria semântica indivíduo, conforme (1) e (2), respectivamente Antarctica e presente; já em (3), a categoria semântica é um estado de coisas (custo). O segundo subato, por sua vez, pode ter como núcleo um indivíduo, como papel envelopes, tinta e cadernetas, em (3), e quantidade como 115,00 ou 10.80 em (4). É importante observar que, por influência do conteúdo contextual, o núcleo do subato pode não ser expresso, como ocorre em (1) e (4), em que respectivamente o núcleo do subato atributivo (cerveja) e do subato referencial (colchões) não está expresso, por ser recuperável na situação discursiva. Casos como esses constituem núcleos ausentes que se definem como um caso de elipse indicativa de uma relação anafórica com uma descrição precedente de cerveja e de colchões.

Essas construções, embora destituídas de verbo, constituem, neste nível, uma predicação, ou seja, uma 
propriedade configuracional, que é o núcleo de um estado de coisas. Propriedades configuracionais compõem o inventário de moldes de predicação relevantes para uma língua. De modo geral, uma propriedade configuracional contém uma propriedade (f), uma entidade de zero ordem, que se aplica a indivíduos $(\mathrm{x})$, entidades de primeira ordem, constituindo uma entidade de segunda ordem ou estado de coisas (e). Dependendo da valência quantitativa e qualitativa da propriedade, os moldes de predicação de uma língua podem variar.

No corpus, foram encontrados três moldes de predicação. O mais recorrente é o de classificação, que se caracteriza por conter duas unidades semânticas ontologicamente idênticas, correspondentes, no nível interpessoal, a um subato de referência e a um subato de atribuição. A unidade atributiva, no entanto, é sempre sintagmática e nunca lexical. Assim, o molde de classificação é genericamente representado em (6).

$$
\text { (6) } \begin{aligned}
& \mathrm{T} \quad \mathrm{R} \\
& \left(\mathrm{f}_{1}:\left[\left(\mathrm{v}_{1}\right)\left(\mathrm{v}_{2}\right)_{\varphi}\right]\left(\mathrm{f}_{1}\right)\right)^{6} \\
& \left(\text { em que }\left(\mathrm{v}_{1}\right) \text { e }\left(\mathrm{v}_{2}\right)\right. \text { são da mesma categoria semântica) }
\end{aligned}
$$

Nas ocorrências (1) e (2), repetidas aqui por conveniência, assim como em (7) e (8), extraídas da internet, há duas unidades que designam categorias semânticas idênticas. Em (1), (2) e (7), há dois indivíduos (Antárctica-(cerveja); presente-colchões; Kaiser-cerveja). Já em (8), a categoria semântica relacionada pelos dois subatos é Lugar (Pão de Açúcar-lugar), sendo então o molde de predicação para (1), (2) e (7) representado em (9), e para (8), em (10).

${ }^{6}$ Nesta representação, v significa variável, $\varphi$ representa uma função, seja pragmática seja semântica.

(1) ANTARCTICA | Simplesmente a melhor. [1AnunXX2CE]

(2) UM PRESENTE RÉGIO | PARA O DIA | DAS MÃES || COLCHÕES DE MOLAS | DIVINOBEL | (1AnunXX2CE)

(7) Kaiser Uma grande cerveja (publicinove.com.br/70slogans-criativos-de-marcas-famosas-para-voce-seinspirar/) 
(8) Pão de Açúcar Lugar de gente feliz. (https://wwww. mensagenscom amor.com/frases-de-propaganda)

(9) $\mathrm{T} \quad \mathrm{R}$

$$
\left(f_{1}:\left[\left(x_{1}\right)\left(x_{2}\right)_{\varphi}\right]\left(f_{1}\right)\right)
$$

'Antárctica simplesmente $a$ melhor (cerveja)'

'um presente régio para o dia das mães colchões de molas divinobel'

'Kaiser uma grande cerveja'.

(10) $\mathrm{T} \quad \mathrm{R}$

$$
\left(f_{1}:\left[\left(l_{1}\right)\left(l_{2}\right)_{\varphi}\right]\left(f_{1}\right)\right)
$$

'Pão de Açúcar lugar de gente feliz'.

A natureza atributiva do $\mathrm{Np}$ predicativo é evidente pelo fato de que ele só pode ser referido anaforicamente por meio de elementos que são usados para predicados, como o pronome demonstrativo neutro isto:

(1) 'Antárctica simplesmente a melhor (cerveja)'. Isto é o que ela é.

(2) 'um presente régio para o dia das mães colchões de molas divino bel'. Isto é o que eles são.

(7) 'Kaiser uma grande cerveja'. Isto é o que ela é.

(8) 'Pão de Açúcar lugar de gente feliz'. Isto é o que ele é.

A ocorrência (3), por outro lado, exemplifica um caso de predicação de um lugar com uma propriedade relacional, já que pelo custo corresponde a um subato atributivo. Ele não é argumento do verbo ser, que, por ser uma cópula suporte, é introduzido apenas no nível morfossintático. A expressão pelo custo como um todo designa uma propriedade e, ao mesmo tempo, contém uma predicação referencial custo. Para explicar essa dupla natureza da construção, a propriedade relacional 
em si é representada como em (11), já o molde de predicação como um todo é representado em (12).

(11) $\mathrm{T} \quad \mathrm{R}_{1}$
$\left(\mathrm{f}_{1}:\left(\mathrm{v}_{1}\right)_{\varphi}\left(\mathrm{f}_{1}\right)\right)$

(12) $\begin{array}{lll}\mathrm{T} & \mathrm{R} & \mathrm{R}\end{array}$

$$
\left(f_{1}:\left[\left(f_{2}:\left(v_{1}\right)_{\varphi}\left(f_{2}\right)\right)\left(v_{2}\right)_{\varphi}\right]\left(f_{1}\right)\right)
$$

O molde de predicação relacional pode ter várias instanciações específicas. No caso de (3), a propriedade é expressa como um estado de coisas (custo), que se aplica a indivíduos (papel, envelopes, tinta, cadernetas), gerando uma predicação não dinâmica, conforme representado em (13). Já em (4), parafraseada por colchão de SOLTEIRO por 115,00 ou 10.80 mensais, a propriedade é expressa pela categoria quantidade (115,00 ou 10.80 mensais), que se aplica a um indivíduo ((colchão de) solteiro), tendo então a representação em (14).

(13) $\left(\mathrm{f}_{1}:\left[\left(\mathrm{f}_{2}:\left(\mathrm{e}_{1}\right)_{\varphi}\left(\mathrm{f}_{2}\right)\right)\left(\mathrm{x}_{2}\right)_{\varphi}\right]\left(\mathrm{f}_{1}\right)\right)$

'Tambem (sic) pelo custo, papel envelopes (sic), tinta, cadernetas etc.'

(14) $\left(\mathrm{f}_{1}:\left[\left(\mathrm{f}_{2}:\left(\mathrm{q}_{1}\right)_{\varphi}\left(\mathrm{f}_{2}\right)\right)\left(\mathrm{x}_{2}\right)_{\varphi}\right]\left(\mathrm{f}_{1}\right)\right)$

'(colchão de) SOLTEIRO à vista apenas 115,00 ou 10.80 mensais'

As ocorrências (15) e (16), também extraídas da internet, atestam que essas estruturas podem ser formadas por uma predicação contendo uma propriedade de um lugar, cujo molde geral de predicação é sempre constituído de um predicado (um subato de atribuição) e de um argumento (subato de referência), conforme representado em (17). Nesse caso, a categoria semântica do argumento (v) pode variar: indivíduo (x), propriedade (f), estado de coisas (e) ou conteúdo proposicional $(\mathrm{p})$. 
(15) Caninha 51 Uma boa ideia (publicinove.com.br/70slogans-criativos-de-marcas-famosas-para-voce-seinspirar/)

(16) Carlton Um raro prazer (publicinove.com.br/70slogans-criativos-de-marcas-famosas-para-vocese-inspirar/)

(17)

$$
\begin{array}{cc}
\mathrm{T} & \mathrm{R} \\
\left(\mathrm{f}_{1}:\left[\left(\mathrm{f}_{2}\right)\right.\right. & \left.\left.\left(\mathrm{v}_{1}\right)_{\varphi}\right]\left(\mathrm{f}_{1}\right)\right)
\end{array}
$$

Assim, o molde de predicação de (15) e (16) apresentase como em (18), observando-se que em (15) o predicado é um conteúdo proposicional (ideia) e, em (16), um estado de coisas (prazer), mas a variável, nos dois casos, é um indivíduo, respectivamente caninha e carlton.

$$
\begin{array}{cl}
\mathrm{T} & \mathrm{R} \\
\left(\mathrm{f}_{1}:\left[\left(\mathrm{f}_{2}\right)\right.\right. & \left.\left.\left(\mathrm{x}_{1}\right)_{\varphi}\right]\left(\mathrm{f}_{1}\right)\right)
\end{array}
$$

Caninha 51 Uma boa ideia

Carlton Um raro prazer

\footnotetext{
${ }^{7} \mathrm{Na}$ GDF, as principais funções semânticas são Actor, Undergoer $\mathrm{e}$ Locative. Traduzimos Undergoer por Inativo, já que representa a entidade não volitiva m e n t e envolvida no estado de coisas, e Locative, a função semântica tipicamente atribuída a um participante com a categoria semântica Lugar, por Locativo. Assim, para manter o paralelismo, preferimos traduzir Actor por Ativo, embora possa ser perfeitamente traduzido por Ator.
}

Como se vê, as estruturas tratadas aqui são semanticamente expressas por predicação monovalente de três tipos: a propriedade de um lugar, a classificacional e a relacional. Há, assim, sempre uma propriedade que se aplica a uma unidade semântica referencial, constituindo um estado de coisas não dinâmico, em que a entidade a que se aplica a propriedade terá a função semântica Inativo (Undergoer). ${ }^{7}$

Um aspecto importante a ser observado é que informações contextuais e situacionais podem determinar as propriedades dessas estruturas no nível representacional. As informações contextuais e situacionais podem ser de dois tipos: (i) a informação imediata (de curto prazo) recebida do componente gramatical, relacionada a um enunciado particular, que determina a forma assumida pelos enunciados subsequentes; 
e (ii) informações de longo prazo sobre a interação em curso, que influenciam a formulação e a codificação nessa língua.

As informações imediatas, recebidas do componente contextual, permitem a elipse de um constituinte, conforme (4) aqui expandida, indicando uma relação anafórica com a descrição precedente de colchões, podendo ser representada como em (19).

(4) UM PRESENTE RÉGIO | PARA O DIA | DAS MÃES || COLCHÕES DE MOLAS | DIVINOBEL | SOLTEIRO à vista apenas 115,00 ou $\mathbf{1 0 . 8 0}$ mensais | CASAL à vista somente 160,00 ou 15.30 mensais | FABULOSA OFERTA PROBEL | FEIRA DAS CAMAS | F. PEIXOTO, 794 FONES: 21-21-12 - 2156-83. (1AnunXX2CE)

(19)

$$
R_{J} \quad T_{J}
$$

Já as informações de longo prazo propiciam estruturas como (1), uma vez que se apoia no conhecimento de mundo dos interlocutores que identificam Antárctica como o nome de uma cerveja, permitindo que não se expresse o núcleo nominal cerveja no sintagma simplesmente a melhor, representada em (20).

(20)

$$
\begin{gathered}
{\left[\left(\mathrm{R}_{\mathrm{J}}: \quad\left(\mathrm{T}_{\mathrm{J}}\right):\left[\mathrm{T}_{\mathrm{I}} \mathrm{T}_{\mathrm{K}}\right)\right.\right.} \\
\left(\mathrm{e}_{\mathrm{i}}:\left[\left(\mathrm{x}_{\mathrm{j}}: \operatorname{Antarctica}\left(\mathrm{x}_{\mathrm{j}}\right)_{\phi}\right)-\left[\left(\mathrm{x}_{\mathrm{j}}:\left(\mathrm{f}_{1}: \operatorname{simplesmente}\left(\mathrm{f}_{\mathrm{f}}\right)\left(\mathrm{f}_{\mathrm{k}}:\right.\right.\right.\right.\right.\right. \\
\text { melhor } \left.\left.\left.\left(\mathrm{f}_{\mathrm{k}}\right)\left(\mathrm{x}_{\mathrm{j}}\right)\right)\right]\left(\mathrm{e}_{\mathrm{j}}\right)\right)
\end{gathered}
$$

Antárctica simplesmente a melhor

\subsection{Análise da codificação morfossintática e fonológica}

Essas construções, assim formuladas nos níveis interpessoal e representacional, são codificadas, no nível morfossintático, como uma expressão linguística, composta de dois sintagmas, correspondentes a subatos no nível interpessoal. Nos exemplos de (1), (2), (3) e (4), os subatos de referência são 
todos representados por um sintagma nominal (Np), enquanto os subatos de atribuição podem ser representados ou por um sintagma nominal (Np), como em (1), (2) e (4), ou por um sintagma preposicional (Prep), como em (3). Para deixar clara essa classificação categorial, repetimos aqui, por conveniência, os exemplos (1) e (3) com a devida rotulação morfossintática:
$R_{\text {TOP }}$
$\mathrm{Np}$
(1) antárctica
$\mathrm{T}_{\text {FOC }}$
$\mathrm{Np}$
simplesmente a melhor (cerveja)
$\mathrm{T}_{\text {TOP }}$
Prep
$R_{\mathrm{FOC}}$
(3) tambem pelo custo,
$\mathrm{Np}$
papel enveloppes, tinta, cadernetas etc.

Segundo Carone (1986, p. 51), apesar de tentador, é perigoso supor, nesse tipo de frase, a elipse do verbo ser. É tentador, porque parece facilitar a compreensão da sentença, e perigoso, porque induz ao erro, tendo em vista que não se pode supor a elipse de algo que não existe. De fato, não é producente analisar essas estruturas morfossintaticamente como se resultassem da elipse do verbo ser. Na GDF, só se requer a inserção de cópula em predicações com predicado não verbal para suprir, na realização de um subato atributivo, a ausência do elemento verbal, indicando tempo, modo e aspecto. Assim, para essa teoria, não há elisão de verbo.

Ocorrências como (1), (2), (7) e (8) podem perfeitamente ser reconstruídas com o uso da cópula suporte, como em (1)a, (2)a, (7)a e (8)a. A análise da paráfrase, entretanto, não pode ser a mesma e nem substituir a análise da ocorrência propriamente dita, uma vez que fere o pressuposto de que as propriedades dos enunciados são adaptáveis aos objetivos comunicativos do usuário em interação com seus interlocutores.

(1)a 'Antárctica é simplesmente a melhor (cerveja)'.

(2)a 'um presente régio para o dia das mães é/são colchões de molas divino bel'.

(7)a 'Kaiser é uma grande cerveja'.

(8)a 'Pão de Açúcar é lugar de gente feliz'. 
Além disso, nem sempre a reconstrução com a cópula preenche satisfatoriamente a "lacuna" verbal, resgatando a predicação pretendida. A ocorrência (3), por exemplo, seria mais adequadamente parafraseada com o uso do verbo haver (cf. 3a), indicando assim uma predicação de existência, enquanto (4) teria como paráfrase mais adequada uma predicação com uma propriedade de dois lugares, como o verbo custar (cf. 4a). A ocorrência (21), por outro lado, exigiria uma predicação com o verbo ter, conforme (21)a.

(3)a. Tambem pelo custo, há papel enveloppes, tinta, cadernetas etc.

(4)a. [colchão de] SOLTEIRO custa à vista apenas 115,00 ou 10.80 mensais

(21) CASA PRIMOR | TUDO PARA PÁSSAROS E AVES (1AnunXX2CE)

(21)a CASA PRIMOR tem TUDO PARA PÁSSAROS E AVES

Isso indica que cada instanciação desse tipo de estrutura deve ser interpretada caso a caso, não permitindo generalizações, tornando fraca explanatoriamente uma teoria que postule lacuna. Não é esse o caso da GDF, que consegue explicar a variação de forma entre as línguas em termos de cognição e comunicação humanas, assumindo que os enunciados são variáveis, mas limitados pelas necessidades comunicativas dos usuários.

A análise morfossintática mostra ainda um fato interessante: as construções que, no nível representacional, correspondem a uma predicação de classificação admitem a paráfrase apenas com o verbo ser; já as construções correspondentes a uma predicação relacional permitem paráfrases com vários tipos de verbo, não se restringindo a um verbo específico, o que confirma tratar-se de predicações distintas.

É nesse nível, entretanto, que se revela uma importante propriedade desse tipo de construção, que é a projeção de exigências pragmáticas, próprias do nível interpessoal, na ordenação dos constituintes, propriedade do nível morfossintático. Como se pode constatar, com efeito, nas 
ocorrências (1), (2), (3) e (4), o subato tópico ocupa a primeira posição na expressão linguística. Pezatti (2014) observa que, em português, os constituintes tópicos são marcados pela posição inicial na sentença, enquanto constituintes focos se alocam sempre na posição final, fazendo um contrabalanço pragmático no domínio da oração. Nas estruturas aqui tratadas, o sintagma na função de tópico ocorre sempre na primeira posição $\left(\mathrm{P}^{\mathrm{I}}\right)$; já o sintagma na função de foco ocupa a posição final $\left(\mathrm{P}^{\mathrm{F}}\right)$, obedecendo ao princípio de estabilidade funcional, que requer que constituintes com a mesma especificação funcional, interpessoal ou representacional, sejam colocados na mesma posição relativa a outras categorias, conforme respectivamente representado em (1b), (2b), (3b) e (4b).

\section{Sintagma ${ }_{\text {тор }}$}

PI

(1)b antárctica

(2)b um presente régio para o dia das mães

(3)b também pelo custo,

(4)b solteiro
Sintagma $_{\text {FOC }}$

$P^{F}$

simplesmente a melhor

colchões de molas divinobel

papel enveloppes, tinta, cadernetas etc.

à vista apenas 115,00 ou 10.80 mensais

Com relação ao nível fonológico, as estruturas aqui tratadas representam uma frase entonacional (IP), composta por duas frases fonológicas. A frase entonacional se caracteriza por apresentar um núcleo, ou seja, um ponto tonal localizado em uma ou mais sílabas, entendido como um operador de queda ou de elevação, essencial para a interpretação do sintagma como um todo. Cada frase fonológica (PP), independentemente do grau de sua própria camada interna, contém uma sílaba mais fortemente acentuada do que as demais circundantes. $\mathrm{Na}$ frase entonacional, uma das frases fonológicas, geralmente a última da sequência, exibe um movimento de pitch local na sílaba mais acentuada. Assim, em (1), repetida aqui por conveniência, a frase fonológica Antarctica tem tar como a sílaba mais forte, enquanto na frase fonológica simplesmente a melhor a sílaba mais forte é lhor, que também constitui o pitch local da frase entonacional. 
(1) ANTARCTICA | Simplesmente a melhor. [1AnunXX2CE]

Na escrita, essa propriedade fonológica é representada de várias maneiras. Nos dados analisados, o limite entre as frases fonológicas pode não ser marcado, como se observa em (22). Outras vezes, o limite é marcado por pontuação, seja pelo emprego de ponto final, como (23), seja pelo de vírgula, como (3), repetida aqui por conveniência. É também comum estabelecer a fronteira fazendo uso da disposição gráfica, como linhas diferentes, conforme (2)c e (1)c, para cada frase fonológica, marcado por barras ( ||$, \mid)$ na transcrição em (2), e por maiúsculas no início de cada uma delas, em (1).

(22) CASAL à vista somente 160,00 ou 15.30 mensais | FABULOSA OFERTA PROBEL | FEIRA DAS CAMAS | F. PEIXOTO, 794 FONES: 21-21-12 - 2156-83. (1AnunXX2CE)

(23) Nacional | Gás Butano. | Calor Humano | de Norte a Sul. || [1AnunXX2CE]

(3) Tambem pelo custo, papel enveloppes, tinta, cadernetas etc.|As vendas pelo custo são só à dinheiro.|Rua 2, casa número 46. (A Notícia, dezembro de 1898).

(2)c UM PRESENTE RÉGIO | PARA O DIA | DAS MÃES II

COLCHÕES DE MOLAS | DIVINOBEL

(1)c ANTARCTICA |

Simplesmente a melhor.

\section{Considerações finais}

Como se deduz da discussão, a frase nominal, formada por equiordenação sintagmática, serve apropriadamente a um gênero discursivo, como o anúncio e a propaganda. Em outras palavras, aspectos do contexto sistematicamente motivam determinadas formas de enunciados, como os aqui apresentados. Manifestando-se por meio de expressão linguística curta, que 
não requer uma decifração cognitivamente custosa em termos de tempo e de atenção, esse tipo de construção sugere uma imagem mais incisiva (JUBRAN, 1985), o que possibilita o alcance imediato do objetivo do anúncio, que é o de chamar a atenção do receptor e obter um consenso emocional que se traduzirá na adesão dele às suas propostas (PEZATTI, 1988). O uso dessas construções no discurso para convencer e persuadir (BENVENISTE, 1950) tem suas razões assentadas no fato de elas exprimirem uma verdade absoluta, especialmente porque, destituídas de verbo, essas estruturas não dispõem das configurações do nível representacional que especificam o tempo, o modo e o aspecto do estado de coisas, eximindose, portanto, de estabelecer em uma relação temporal com o locutor, senão indiretamente em função da situação discursiva em que se inscrevem na comunicação.

Apresentam, por isso, forte dependência tanto da situação em que se encontram falante e destinatário, quanto de informações recebidas do componente gramatical, de tal modo que as informações recebidas do componente contextual permitem remissões a outros constituintes. Nesse jogo linguístico, essas construções se comportam como uma oração por se submeterem a regras e princípios intraoracionais: constituem predicações, ou seja, uma relação núcleodependente; permitem anáfora; e obedecem a princípios de ordenação dos constituintes, como o princípio de estabilidade funcional, colocando constituintes tópicos em posição inicial e focos em posição final.

Assim, vista da perspectiva da GDF, a seleção desse tipo de estrutura é uma estratégia de adaptação aos objetivos comunicativos do usuário, tanto em termos de formulação pragmática e semântica, quanto em termos de codificação morfossintática e fonológica. Esse comportamento confirma o pressuposto de que a sistematicidade existente no uso da língua pode ser formalizada em todos os níveis de representação, conforme se observa nos quadros a seguir, relativos às ocorrências (11), (12), (13) e (14). 
Quadro 1 - Relativo à ocorrência (11)

\begin{tabular}{|l|l|l|}
\hline NI & $\mathrm{R}_{\text {TOP }}$ & $\mathrm{T}_{\mathrm{FOC}}$ \\
\hline $\mathrm{NR}$ & $\mathrm{x}$ & $\mathrm{f}$ \\
\hline $\mathrm{NM}$ & $\mathrm{Np}$ & $\mathrm{Np}$ \\
\hline NF & PP & $\mathrm{PP}$ \\
\hline$(11)$ & antárctica & simplesmente a melhor (cerveja) \\
\hline
\end{tabular}

Quadro 2 - Relativo à ocorrência (13)

\begin{tabular}{|l|l|l|}
\hline $\mathrm{NI}$ & $\mathrm{T}_{\mathrm{TOP}}$ & $\mathrm{R}_{\mathrm{FOC}}$ \\
\hline $\mathrm{NR}$ & $\mathrm{x}$ & $\mathrm{x}$ \\
\hline $\mathrm{NM}$ & $\mathrm{Np}$ & $\mathrm{Np}$ \\
\hline $\mathrm{NF}$ & $\mathrm{PP}$ & $\mathrm{PP}$ \\
\hline$(13)$ & $\begin{array}{l}\text { um presente régio } \\
\text { para o dia das mães }\end{array}$ & colchões de molas divinobel \\
\hline
\end{tabular}

Quadro 3 - Relativo à ocorrência (14)

\begin{tabular}{|l|l|l|}
\hline NI & $\mathrm{T}_{\text {TOP }}$ & $\mathrm{R}_{\mathrm{FOC}}$ \\
\hline $\mathrm{NR}$ & $\mathrm{e}$ & $\mathrm{x}$ \\
\hline $\mathrm{NM}$ & Prep & $\mathrm{Np}$ \\
\hline NF & PP & PP \\
\hline$(14)$ & também pelo custo, & $\begin{array}{l}\text { papel enveloppes, tinta, } \\
\text { cadernetas etc. }\end{array}$ \\
\hline
\end{tabular}

Quadro 4 - Relativo à ocorrência (15)

\begin{tabular}{|l|l|l|}
\hline NI & $R_{\text {TOP }}$ & $\mathrm{T}_{\text {FOC }}$ \\
\hline NR & $\mathrm{x}$ & $\mathrm{q}$ \\
\hline $\mathrm{NM}$ & $\mathrm{Np}$ & $\mathrm{Np}$ \\
\hline $\mathrm{NF}$ & $\mathrm{PP}$ & $\mathrm{PP}$ \\
\hline$(15)$ & (cama) solteiro & $\begin{array}{l}\text { à vista apenas } 115,00 \text { ou } 10.80 \\
\text { mensais }\end{array}$ \\
\hline
\end{tabular}

Entendemos, como Dik (1997, p. 12) e Mackenzie (1998, p. 296), que muito da interação do dia a dia é altamente implícito por natureza, e enunciados inteiros que são geralmente analisados como elípticos e incompletos, denominados por Bühler (1990, p. 323) "trapos irritantes do discurso humano", 
acabam por se constituir em ocorrências 'exemplares' do caráter implícito da conversação. Assim, mais do que realizações fragmentárias de estruturas complexas subjacentes, essas construções são completas por si mesmas se levados seriamente em conta os rastros que deixam na situação em que ocorrem como guias para a interpretação do interlocutor.

\section{REFERÊNCIAS}

BENVENiSTE, É. A frase nominal. In: ___. Problemas de linguística Geral. Campinas, SP: Pontes, 1976. p. 176-182.

BÜHLER, K. Theory of language (trasn. of Sprachtheorie, 1934). Amsterdam/Philadelphia: John Benjamins, 1990.

CARONE, F. B. Morfossintaxe. São Paulo: Ática, 1986.

DIK, S. The Theory of Functional Grammar. Part I: The Structure of the Clause. Berlin: New York: Mouton de Gruyter, 1997.

FORTILLI, S. As construções não verbais no português falado no interior do Estado de São Paulo. Dissertação (Mestrado em Estudos Linguísticos). UNESP, Instituto de Biociências, Letras e Ciências Exatas, São José do Rio Preto, 2007.

HENGEVELD, K.; MACKENZIE, J. L. Functional Discourse Grammar: A typologically-based theory of language structure. Oxford: Oxford University Press, 2008.

HJELMSLEV, L. El verbo y la frase nominal. In: Ensayos Lingüísticos. Madrid: Gredos Editorial, 1971.

JUBRAN, C. C. A. S. A metáfora e a metonímia na linguagem da propaganda. Estudos Linguísticos. São Paulo. n.10 (1), p. 27-31, 1985.

KATO, M. Free and dependent small clauses in Brazilian Portuguese. DELTA. São Paulo. n. 23, p. 85-111, 2007.

MACKENZIE, J. L. The basis of syntax in the holophrase. In: HANNAY, M. and BOLKESTEIN, A.M. (eds.), Functional Grammar and verbal interaction. Amsterdam: Benjamins, 1998. p. 267-295. 
PEZATTI, E. G. A ambiguidade na linguagem da propaganda. Alfa-Revista de Linguística (São Paulo). n. 32, p. 85-93, 1988.

A ordem das palavras em português. São Paulo: Parábola Editorial, 2014.

. Holófrase em anúncios dos séculos XIX e XX. In: Simpósio Mundial de Estudos em Língua Portuguesa (SIMELP), 2017. Anais - Santarém, Portugal. (inédito).

PEZATTI, E. G.; D' ANNIBALE, A. M.; BOIAGO, S. R. As frases nominais no português oral e escrito. Estudos Linguísticos. São Paulo. n. 28, p. 101-111, 1999.

PINHEIRO, C. S. O aspecto como fonte dos diferentes graus de (a)gramaticalidade nas miniorações livres adjetivais. Estudos Linguísticos. São Paulo. n. 38 (1), p. 359-373, 2009.

SIBALDO, M. A. Sobre a estrutura interna das small clauses livres no português brasileiro. Estudos Linguísticos. São Paulo. n. 40 (1), p. 231-240, 2011.

ZENDRON DA CUNHA, K.; CARPES, D. R. P. Small clauses livres e sentenças clivadas: comportamento entonacional e sintaxe. Diadorim: revista de estudos linguísticos e literários. n. 17 (2), p. 107-125, 2015. 


\section{Abstract \\ Small Clauses in Advertisements in a Discursive-Functional Perspective}

This study aims at analyzing small clause from Functional-Discourse Grammar viewpoint (Hengeveld and Mackenzie 2008) on the basis of language use in social context whose occurrences were extracted from XIX and XX century advertisements. The phenomenon examined involves constructions consisting of two phrases, which are related to the informational structure Topic/Focus, as in Ice cold pool ... never again, ., showing the following features (i) are common constructions in languages; (ii) require a type of study that does not focus on isolated clauses, since they depend on the communicative situation in which they are used; and (iii) are subjected to intra-clausal rules and principles. The selection of this structure is a user's adaptive strategy to her/his communicative goals in the interaction situation both in terms of pragmatic and semantic formulation and in terms of morphosyntactic and phonological encoding, as predicted by FDG.

Keywords: functional grammar. small clause. nominal phrase. verbless clause. 